\title{
Políticas mercantiles en espacios reduccionales fronterizos: Modelos, reapropiaciones y disputas (Río de la Plata, siglo XVIII)
}

\author{
Commercial policies in frontier reductions. Models, \\ reappropriations and disputes (Río de la Plata, 18th \\ century)
}

Lía Quarleria* (i) https://orcid.org/0000-0002-0738-6407
Recibido el 1 de febrero de 2017. Aceptado el 24 de octubre de 2017.

${ }^{*}$ Autor para correspondencia: Lía Quarleri, correo electrónico: liaquarleri@yahoo.com.ar

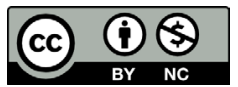

Esta obra está protegida bajo una Licencia Creative Commons Atribución-NoComercial 4.0 Internacional.
${ }^{a}$ Universidad Nacional de San Martín, Instituto de Altos Estudios Sociales y Consejo Nacional de Investigaciones Científicas y Técnicas, Argentina, correo electrónico: liaquarleri@yahoo.com.ar

\section{Resumen}

El objetivo del artículo es analizar el modelo mercantil de intervención borbónica en las reducciones guaraníes atendiendo a las adaptaciones, respuestas y conflictos derivados. La metodología utilizada es el análisis de fuentes históricas desde una perspectiva antropológica. En primer lugar, se esclarecieron las directrices borbónicas del libre comercio en las misiones guaraníes. En segundo lugar, se plasmaron las controversias existentes entre las autoridades coloniales. Por último, se dieron indicios de la participación indígena en dicho comercio. Las limitaciones estuvieron dadas por el sesgo de las propias fuentes oficiales. El valor del estudio reside en la realización de un análisis articulado a partir de las normativas, los conflictos y la agencia indígena. Se llegó a la conclusión de que la intermediación política configurada para obstruir el libre acceso de la población misionera al nuevo sistema mercantil generó un proceso contrario. Asimismo, que este proceso se dio dentro de un poder colonial fragmentado.

Palabras clave: burocracia borbónica, prácticas mercantiles, reducciones guaraníes, fronteras de Río de la Plata.

\section{Abstract}

The aim of this paper is an analysis of the commercial policy implemented by the colonial bureaucracy on the Guarani Reductions, also the adaptations, responses and conflicts this process originated. The historical sources are analyzed from an anthropological perspective. First, the colonial commercial policies applied on the Guarani missions are put in context. Second, the controversies within the colonial administration are interpreted. Finally, indications of indigenous participation in this trade is described. The bias found in the official documents is a limitation of

CÓMO CITAR: Quarleri, L. (2018). Políticas mercantiles en espacios reduccionales fronterizos: Modelos, reapropiaciones y disputas [Commercial policies on frontier reductions. Models, reappropriations and disputes (Río de la Plata, 18th century)]. Estudios Fronterizos, 19, e003. doi:10.21670/ref.1803003 
this study. Its value, however, lies in an analysis which brings together regulations, conflicts and indigenous agency. It is concluded that the political mediation designed to hinder the missionary population's free access to the new commercial system had the opposite effect.

Keywords: Bourbon bureaucracy, commercial practices, Guarani Missions, Rio de la Plata frontiers.

\section{Introducción}

En 1788, el gobernador intendente de Buenos Aires Francisco de Paula Sanz solicitó a las autoridades hispanas departamentales de las misiones guaraníes, bajo su jurisdicción, que le informaran sobre los beneficios o perjuicios de las prácticas mercantiles en aquellos pueblos. Uno de los temas que le inquietaba era la entrada y salida de comerciantes provenientes de jurisdicciones vecinas, sin control aparente, tras lo cual traían bebidas, se vendían productos comunales a bajo valor y se compraban otros de forma particular sin una consideración general de las conveniencias. Las respuestas obtenidas a tal solicitud expresaron una gama de opiniones y posturas que no solo dieron cuenta de la existencia de pugnas de intereses que incluían a las autoridades hispanas y guaraníes de las misiones, sino que también mostraron los laberínticos senderos que las prácticas mercantiles habían tomado en las reducciones tras la expulsión de los jesuitas. Al respecto, la apertura mercantil de los pueblos había generado un conjunto de consecuencias no buscadas, intensificadas con la radicación de una burocracia administrativa no preparada e interesada en obtener beneficios sin contemplaciones.

Una mirada general al problema incitaba a pensar en las contradicciones implícitas asociadas a la utopía del mercado, propia de la época, plasmada en las ordenanzas escritas para introducir, regular y fiscalizar las prácticas mercantiles en las misiones. ${ }^{1}$ Estas habían sido concebidas por el gobernador Francisco de Bucarelli, encargado de la extradición de los jesuitas, con el objetivo de reglar, entre otras cosas, la nueva política económica en los pueblos guaraníes tras la expulsión. ${ }^{2}$ Con ciertas diferencias, las reglamentaciones y directrices posteriores reprodujeron los vínculos entre comercio, progreso, felicidad e igualdad, contenidos en la propia categoría de "comercio ilustrado". Pese a advertir, poco tiempo después, que la economía misionera se había

\footnotetext{
${ }^{1}$ Los jesuitas habían estructurado la economía misionera partiendo de ciertas pautas de organización guaraní. Una vez fundados los pueblos de reducción, los ignacianos organizaron una modalidad de producción familiar y otra comunal. La primera consistía en el cultivo de productos de subsistencia en parcelas de tierras obtenidas por familias por su pertenencia a una parcialidad o cacicazgo. La segunda se basaba en la producción en tierras del común de los pueblos con el objeto de obtener bienes que eran destinados al almacenamiento, el intercambio con otras reducciones y a la comercialización regional. El proceso de comercialización estuvo centralizado en manos de los jesuitas. Los ingresos por venta de productos como la yerba mate cubrían el pago del tributo a la Corona, el sustento de los religiosos, el pago de salarios a los miembros del cabildo indígena, la compra de bienes y herramientas no producidos internamente y la construcción, inversión y mantenimiento de edificios, talleres e instalaciones diversas, entre otras cosas.

${ }^{2}$ Las reducciones guaraníes conformaban, entonces, un complejo de treinta pueblos localizados en las actuales fronteras de Paraguay, Brasil, Argentina y Uruguay. Hacia la fecha de la expulsión, estaban pobladas por 90000 personas, en una zona históricamente disputada con los portugueses del Brasil, asentadas sobre vías y rutas fluviales que conectaban con los principales puertos y mercados de la región platense.
} 
deteriorado drásticamente ninguno de los funcionarios, intervinientes o consultados, objetó la compra y venta de productos misioneros, en gran medida, porque estaban involucrados.

En este artículo nos proponemos analizar las bases ideológicas del modelo de intervención borbónica sobre el comercio misionero, dando cuenta tanto de las diferentes concepciones en juego como de las disputas de intereses entre las distintas instancias de la burocracia y el poder colonial. Se busca poner de relieve, en particular, la controversia generada en torno a la libre circulación de comerciantes españoles dentro de las misiones así como las miradas contrastadas sobre la participación de la población guaraní en la compra-venta de los bienes reduccionales. Al respecto, partimos de la hipótesis de que la intermediación política y administrativa montada en función de la supuesta incapacidad indígena para comerciar, generó un proceso contrario: la participación en el mercado se manifestó tanto a través del comercio no fiscalizado de recursos ganaderos, como en la adquisición de bienes a escondidas de los administradores. La alusión a estas prácticas, aunque indirecta, quedó inmersa en las argumentaciones de los funcionarios consultados que a su vez respondían a diferentes miradas sobre el control de los recursos misioneros. ${ }^{3}$

La disputas sobre el destino de los recursos de los pueblos indígenas se inserta dentro de una problemática mayor de la historia colonial en América. Al respecto, existen amplias contribuciones sobre los efectos del colonialismo mercantil en Hispanoamérica focalizadas en las situaciones diferenciales en relación con las economías regionales, las presiones fiscales, las demandas laborales, las estructuras cacicales y las estrategias comunales. También se cuenta con diferentes estudios sobre la participación indígena en los circuitos mercantiles en zonas neurálgicas virreinales y jurisdicciones marginales, como entre espacios urbanos y rurales y en fronteras de colonización. ${ }^{4}$ En particular, el reformismo borbónico al aumentar el control sobre las redes mercantiles locales y pretender mayores ingresos impositivos presionó a las economías comunales. Por su parte, en el Río de la Plata, dada la situación fronteriza con las colonias portuguesas, convergieron los efectos tanto de las reformas borbónicas como pombalinas dentro de renovadas competencias por el control de los mercados, la mano de obra indígena, los recursos, las vías navegables y los espacios productivos.

El proyecto reformista borbónico, en sus múltiples vertientes, se aplicó a las misiones guaraníes tras la expulsión de los jesuitas con particulares contradicciones. La instalación de una administración española, la apertura de las misiones a los diferentes intereses mercantiles y la instalación de nuevos residentes en los pueblos desencadenaron un profundo deterioro del complejo reduccional. La historiografía especializada indagó extensamente en las transformaciones e impactos negativos de este proceso sobre los pueblos en sintonía con la pérdida poblacional, por mortalidad y fuga, el deterioro de las relaciones de autoridad étnica y la malversación

\footnotetext{
${ }^{3}$ La consideración de la participación indígena a partir de documentación oficial resulta enriquecida a la luz de perspectivas de indagación no lineales como la expresada a través de la noción de Historia a contrapelo de Walter Benjamin (1982).

${ }^{4}$ Cabe mencionar la compilación de Jorge Silva Riquer y Antonio Escobar Ohmstede (2000), la publicación coordinada por Silvia Palomeque y Fernando Jumar (2007) y el dossier compilado por Sara Ortelli (2011). En particular interesa rescatar aquellos estudios que den cuenta de los intercambios económicos dentro de circuitos ilegales o informales, como parte del universo mercantil, así como de los "mercados fronterizos" configurados a partir de ellos (Cavieres, 2011).
} 
administrativa, entre otras cuestiones (Maeder, 1992; Poetniz y Poetniz, 1998). ${ }^{5}$ Todo ello en una coyuntura de creciente demanda externa de cueros que llevó a una expoliación del ganado misionero ${ }^{6}$. Así como en un contexto de ocupación de los espacios circundantes a las misiones, especialmente el de las estancias de los pueblos ganaderos, y de afán por los recursos guaraníes por parte de particulares como de funcionarios públicos (Caletti, 2015).

A partir del análisis de las posiciones encontradas entre los diferentes funcionarios locales y virreinales sobre el comercio misionero con sede en Buenos Aires, buscamos dar cuenta de las controversias ideológicas y competencias por los recursos de los pueblos entre las diferentes instancias del poder colonial. Se partirá del modelo de intervención económica plasmado en las ordenanzas del gobernador Francisco de Bucarelli, para indagar luego en las reapropiaciones que tanto los funcionarios españoles como la población misionera llevó a cabo en medio de intereses encontrados por los beneficios de la comercialización. Es importante, a su vez, considerar las referencias indirectas a la participación indígena a través de los intersticios que dejan los documentos. ${ }^{7}$ La agencia indígena no solo formaba parte de las argumentaciones de los funcionarios coloniales sobre los beneficios o perjuicios de la presencia de mercaderes en los propios pueblos, sino que era referenciada al condenar el trueque o comercialización individual de bienes sin la entronizada intervención de la burocracia borbónica.

\section{Cuerpo jurídico y modelo económico}

Las misiones guaraníes, tras la expulsión de los jesuitas, se transformaron en un paradigmático experimento del nuevo colonialismo borbónico en donde se condensaron los principales ejes del reformismo ilustrado y del reformismo de frontera (Lucena, 1996). ${ }^{8} \mathrm{El}$ encargado de diseñar las bases normativas del nuevo régimen de administración, gobierno y asimilación de la población de las reducciones

\footnotetext{
${ }^{5}$ En un trabajo reciente, Julia Sarreal (2014) presentó una propuesta diferente a la tradicionalmente adoptada por la historiografía al destacar que dentro de un contexto de crisis las preferencias y adaptaciones de los guaraníes jugaron un papel importante al asumir modalidades de acceso a recursos de carácter más individual. Esto, a su vez, se relacionaba con las resistencias al sistema coactivo de producción comunal, expresadas en fugas y quejas por los abusos de los administradores españoles y corregidores guaraníes.

${ }^{6}$ El cambió en la explotación ganadera se dio por la generalización de la vaquería de corambre sin control y el arreo de ganados mansos misioneros de forma clandestina hacia los mercados mineros brasileños, marcando el paso de una ganadería esencialmente para el autoconsumo a una ganadería especulativa y depredadora, volcada a los mercados atlánticos (Moraes, 2007).

${ }^{7}$ Al respecto Sara Ortelli propone una perspectiva metodológica más amplia sobre el estudio de las prácticas económicas de las poblaciones indígenas a partir de alternativas metodológicas que den luz a "ciertos intersticios difíciles de aprehender a través de la documentación que regularmente se utiliza en historia económica" (Ortelli, 2011, p. 4).

${ }^{8}$ Tras la expulsión de los jesuitas, las treinta reducciones se mantuvieron bajo un mismo régimen divididos en dos distritos, el de Paraná y el de Uruguay, dentro de la jurisdicción de Buenos Aires. En 1774 se crearon nuevas agrupaciones llegando a estar los pueblos supeditados a los departamentos de Santiago, Candelaria, San Miguel, Yapeyú y Concepción. Con la Real Ordenanza de Intendentes, los departamentos de Santiago y Candelaria pasaron a depender de Paraguay y los departamentos de Yapeyú, Concepción y San Miguel de la intendencia de Buenos Aires. La ocupación del departamento de San Miguel, en 1801, por Portugal, marcó un hito que se intensificó con el impacto general que produjeron sobre este territorio las guerras independentistas.
} 
fue el gobernador de Buenos Aires Francisco de Paula Bucarelli (1766-1771), responsable también de ejecutar la extradición de los jesuitas en las jurisdicciones bajo su cargo. Las "Instrucciones" de gobierno para las misiones guaraníes se basaron, en parte, en las ordenanzas elaboradas por el reformismo pombalino para los pueblos indígenas amazónicos previamente administrados por los jesuitas (Maeder, 1987). Esta adaptación, que daba cuenta de una matriz ideológica común, respondía a la necesidad del gobernador de elaborar en pocos meses ordenanzas que debían garantizar el proceso de transición de una administración religiosa, asociada al antiguo régimen, a otra que se presentaba como ilustrada y moderna. Para Bucarelli, su gestión, que implicó un impacto no imaginado en el Río de la Plata y en el distrito misionero, fue solo un paso despreciable en su carrera militar. Incluso, como noble militar de formación tradicional, expresó haber respondido a los requisitos del Virrey del Perú, Manuel de Amat y Junyent, siendo este último "más moderno" que él. ${ }^{9}$

Pese a todo, supo plasmar en las ordenanzas los nuevos ideales de organización social de tendencias fisiocrática adaptados a un modelo colonial de corte mercantilista, centralista y regalista con el fin de introducir el "libre comercio" en los pueblos, el acceso a bienes comunales y el cobro de impuestos, ${ }^{10}$ fines para los cuales el control productivo, fluvial y demográfico de una amplia región fronteriza poblada por uno de mayores conglomerados indígenas del virreinato debía quedar bajo esfera absoluta de la Corona española. El comercio libre, amplio y fluido, se concebía como una etapa evolutiva necesaria a los estados modernos, nuevo culto que traería un acabado bienestar a los diferentes estratos jurídico-sociales y que por medios fiscales engrandecería las arcas reales. La nueva política comercial que tomaría, en la región analizada, carácter general tras la creación del virreinato del Río de la Plata fue volcada a través de un arquitectónico constructo en las ordenanzas de Bucarelli para el caso misionero. Al respecto, el gobernador afirmaba que las mismas eran elaboradas:

Deseando en consecuencia de todo que dichos naturales, con la libertad que han recuperado, logren el comercio libre con las provincias circunvecinas, por cuyo medio, no sólo se civilizarán y gozarán del beneficio de la racional sociedad, sino que reportarán también las ventajas y utilidades de hacer valer los frutos que la naturaleza les produce. ${ }^{11}$

El comercio sin teóricas restricciones se constituía en la base de todas las transformaciones proyectadas en esta nueva etapa del colonialismo ibérico en la

\footnotetext{
${ }^{9}$ Luego de ejecutar la extradición de los jesuitas de la región misionera, Bucarelli escribió al conde de Aranda, presidente del Consejo de Castilla, solicitándole lo libere "entre otros disgustos de estar a las órdenes de un virrey que es más moderno que yo en todos los grados y en gobierno tan subalterno como este después de los distinguidos mandos que tuve en España" (Carta de Francisco de Paula Bucarelli y Ursúa al señor conde de Aranda, 1768, p. 10v).

${ }^{10} \mathrm{El}$ concepto de "libre comercio" antecede en este caso al "Reglamento de libre comercio" (1778) elaborado por la corte de Carlos III con el fin de permitir el librecambio comercial de España con sus colonias americanas antes coartado por el monopolio existente con ciertos puertos o polos mercantiles. En ello sopesaron las doctrinas económicas difundidas asiduamente desde Europa y los recientes sucesos en Norteamérica (Wallerstein, 2004, p. 303).

11 "Instrucción a que se deberán arreglar los Gobernadores interinos que dejó nombrados en los pueblos de indios guaraníes del Uruguay y Paraná, no habiendo disposición contraria de Su Majestad, Francisco Bucareli y Ursúa, Candelaria, 23 de agosto de 1768" (Bravo, 1872, p. 324).
} 
región. ${ }^{12}$ Sin embargo, su aplicación en este caso exigía ciertas adaptaciones. Por un lado, en relación con la moneda de cambio, ya que:

No teniendo la moneda giro alguno en los pueblos del Uruguay y Paraná, como no lo tiene aun en las ciudades de españoles más inmediatas a dichos pueblos, es preciso que ínterin hagan su comercio del mismo modo que estas, permutando y trocando los frutos que recojan por los efectos que han menester (Bravo, 1872, p. 325).

Por otra parte, debían imponerse modificaciones en su forma de concreción. Al respecto aunque Bucarelli enfatizaba que en la libertad consistía el "alma del comercio", los beneficios del "comercio recíproco" entre guaraníes e hispanos solo eran posibles, dado el "genio", "carácter" y "aptitud de los "naturales", a través de la intermediación política y administrativa. Desde esta óptica paternalista y colonialista, una "entera libertad" sería "fatal y perjudicial" para los guaraníes de los pueblos, los cuales debían ponerse "a cubierto siguiendo leyes para adultos que tienen defectuoso el uso de la razón". La "indispensable intervención" se haría a través de administradores hispanos que velarían por sus "bienes y contratos" con "celo e integridad". Uno de los aspectos resaltados era que para realizar un contracto comercial a "equidad de precio" las partes debían hablar, leer, escribir y contar en español. Como la mayoría de la población hablaba guaraní no solo aquella libertad era imposible sino que debía enseñarse "a la juventud" el castellano, prohibiendo el uso de su idioma, a través de maestros pagos con frutos de comunidad. La otra cuestión recalcada era que la falta de conocimientos prácticos llevaría a que los "indios" se vieran perjudicados frente a la "astucia y sagacidad natural a todo mercader" e incluso a la de españoles y criollos, con los que ahora convivirían (Bravo, 1872, p. 326). Para ello, en las ordenanzas, se estipuló la instauración de un sistema de controles mutuos. ${ }^{13}$

La supervisión la ejercerían, por un lado, el cabildo indígena de cada uno de los treinta pueblos, con especial injerencia del corregidor guaraní, y en lo extraordinario el protector de natural, funcionario español que fiscalizaría el sistema en caso de desajustes, conflictos o denuncias. Del otro lado, los administradores hispanos en cada reducción, tenientes de gobernador departamentales y un gobernador general de misiones. Finalmente, un administrador general en Buenos Aires, "gestor de los negocios de los indios y curador dativo de sus bienes", que con fianza previa manejaría en última instancia todo el sistema, ya que no solo sería quien recibiría todos los registros de la actividad comercial de los pueblos consignados por los administradores en libros sino que tomaría decisiones generales, a partir de una ganancia porcentual (Bravo, 1872, p. 337). Una compleja ingeniería montada para supervisar y fiscalizar las transacciones, tasar el valor de los bienes, evaluar qué productos vender y qué comprar de acuerdo a la especificidad productiva de cada pueblo a las necesidades y conveniencias de la comunidad. Además, se buscaba articular el intercambio de productos agrícolas, ganado, cueros y bienes

${ }^{12}$ El comercio sacralizado se concebía, además, en las ordenanzas, como medio de comunicación y amistad entre estados, como forma de trascender la mera subsistencia, acumular bienes y con ello propiedad y herencia, como eje de fortalecimiento de la familia como nuevo basamento social y como máxima expresión de libertad de acción de individuos, sociedades y estados.

${ }^{13}$ Este control mutuo apuntaba a la práctica comercial, en sí misma, pero también al resguardo de los bienes en los almacenes comunales, los cuales estarían cerrados y las llaves estarían en posesión del corregidor y del mayordomo, ambos del cabildo indígena, y del administrador español. 
manufacturados con las provincias vecinas de Asunción, Corrientes, Buenos Aires y Santa Fe.$^{14}$ Con ello se pretendía dinamizar el mercado interno redireccionando los beneficios regionales, antes atesorados por los jesuitas, hacia la metrópolis, a través del potencial productivo de los pueblos. A los fines de regular este intercambio se nombrarían tenientes distritales bajo supervisión de la intendencia general de Buenos Aires y del gobernador general de misiones. Finalmente, de las cajas comunes del pueblo se pagarían los sueldos de los empleados y los tributos reales.

Bucarelli, no obstante, sopesó la posibilidad de que se conformaran alianzas desde el ámbito local para la venta o compra de productos salteando los controles de Buenos Aires. En ese sentido, preocupaba tanto la evasión del pago de la alcabala al erario público así como la ausencia de una negociación satisfactoria a los objetivos de alcanzar la autosuficiencia misionera. Además, intranquilizaba la pérdida de control sobre el "alquiler" de mano de obra indígena para trasportes, en canoas y carruajes a particulares sin el pago adecuado de jornales. Por último, inquietaba que la entrada de comerciantes a los pueblos se efectuase de forma permanente interrumpiendo la lógica productiva. La problemática subyacente consistía en el enraizamiento de poderes regionalizados que limitaban el acceso de la metrópoli a los potenciales beneficios extractivos de sus colonias americanas. El centralismo borbónico, representado aquí por Bucarelli, quería revertir este sistema de intermediaciones restringidas, en concordancia con una coyuntura de fuertes cambios en las concepciones de gobierno. La expectativa de ese cambio quedó depositada sobre un nuevo modelo de burocracia, leal a los intereses reales, que idealmente fiscalizara a la población, a los fines impositivos, laborales y productivos, y limitase los efectos de las dinámicas políticas locales en los conflictos de intereses de los funcionarios coloniales.

\section{Disputas por los recursos y denuncias cruzadas}

La política de apertura comercial, implementada bajo una falaz renovación de las condiciones, vínculos y libertades ganadas por la población indígena de los pueblos conllevó múltiples desajustes y deslizamientos y, lejos de actuar como resorte de bienestar afectó condiciones básicas de subsistencia. Por su parte, la población misionera, ante la presencia de nuevos actores sociales, se fragmentó en tanto comunidad estructurada internamente y diversificó sus respuestas ante las nuevas vías de acceso a productos y frente a la introducción de nuevos bienes. Al respecto, las misiones en tiempos jesuitas estaban estructuradas sobre una economía de intercambio mercantil controlada por los misioneros, donde existían intersticios para el trueque

\footnotetext{
${ }^{14}$ La comercialización de yerba, tabaco, azúcar, miel, lienzos y ganado de los pueblos a cambio de enseres domésticos, ropa, herramientas, sal y aceite, entre otros, se haría a través de la entrada de comerciantes a los pueblos o por medio del envío de productos hacia o desde la administración de Buenos Aires y viceversa, por vía fluvial. Los comerciantes solo podrían entrar a los pueblos en los meses de febrero a abril para no interferir con las cosechas y otras labores con supervisión de los administradores (Bravo, 1872, p. 324; Informe solicitado por el superintendente general, Francisco de Paula Sanz, sobre la introducción de bebidas y efectos de comercio en los Pueblos de Misiones guaraníes, 1788 y 1789).
} 
fuera del ámbito reduccional. ${ }^{15} \mathrm{El}$ cambio radicó en que, a partir de las ordenanzas de Bucarelli, la compra y la venta de productos se instaló como eje transversal de la economía, marcó los vínculos cotidianos, amplió la esfera de interacción con otros espacios, puso en juego los bienes misioneros, en particular los recursos ganaderos, así como sus tierras, y dividió a la sociedad. Por su parte, la dirigencia administrativa no funcionó a los fines de encauzar un idealizado armazón de beneficios mutuos. ${ }^{16}$

Los conflictos entre las diferentes instancias de gobierno y administración, por el control de beneficios económicos y preeminencias políticas, se acrecentaron tras la creación del virreinato del Río de la Plata, en 1776, y con el decreto de libre comercio. Un primer síntoma fue una extensa disputa entre el administrador general en los asuntos económicos, Juan Angel de Lascano, en Buenos Aires, y el gobernador de las misiones, en los aspectos políticos y militares, Francisco Bruno de Zabala, con sede en el pueblo de Candelaria. El conflicto expresó rivalidades e intereses personales así como desavenencias frente a las pretensiones de Buenos Aires, en tanto capital del flamante virreinato, por asentar lógicas de obediencias centralizadas donde por largo tiempo habían primado los poderes políticos regionales. De esta forma, las misiones, además de concentrar extensos recursos codiciados por toda la sociedad circundante, pasaron a conformar un escenario de luchas políticas en donde se dirimieron gobernabilidades encontradas. ${ }^{17}$ Por su parte, el territorio misionero cobró mayor visibilidad con la expedición de Límites, derivada del Tratado de San Ildefonso (1777), que empezó las tareas de demarcación en los primeros años de la década de $1780 .{ }^{18}$ Finalmente, las pugnas por definir los beneficios e injerencias del espacio misionero se recrudecieron con la creación de las reales intendencias, en 1784 .

Dentro de este contexto, en 1785, el flamante gobernador intendente de Buenos Aires, Francisco de Paula Sanz, elaboró ordenanzas para reforzar el control y la supervisión de las actividades mercantiles en los pueblos. ${ }^{19}$ Tres años después

${ }_{15}$ Por otra parte, el comercio como intercambio de bienes e incluso de bienes por personas fuera del grupo de pertenencia y a través de códigos transaccionales compartidos fue una práctica identificable entre las sociedades de Tierras Bajas, incluso entre grupos rivales. Estas prácticas sumadas a las lógicas coloniales dieron lugar en el Río de la Plata a los llamados "rescates". Por su parte, dentro de la esfera reduccional jesuita continuaron ciertos niveles de intercambio individual dentro y fuera del espacio misionero, más allá de la centralización y control de la economía por parte de los religiosos (Haubert, 1991; Susnik, 1965).

${ }^{16}$ Cabe aclarar que uno de los hechos que trajo aparejado el nuevo régimen de administración colonial fue la residencia en las misiones de nuevos actores sociales que por sus prerrogativas, su estilo de vida y sus intereses económicos generaron nuevas capas de desigualdad internas y nuevas formas de violencia.

17 Guillermo Wilde (2009) analiza el tema en particular. Al respecto, se detiene en una visita realizada a los pueblos, en 1775, por orden del gobernador de Buenos Aires Juan José de Vértiz y Salcedo, en donde los frailes consultados se refirieron en extenso a la superposición de jurisdicciones políticas dentro y fuera de los pueblos (Wilde, 2009).

${ }^{18} \mathrm{El}$ Tratado se firmó para dirimir las rivalidades fronterizas con los portugueses, quienes se sumaban como actores competitivos en el espacio rioplatense.

${ }^{19}$ El principal adversario de la política centralista de Buenos Aires lo representaba el gobernador Zabala. Al respecto Sanz en una carta dirigida al mismo le escribió que por:

Causa de las desavenencias entre $\mathrm{Vm}$ y los tenientes de gobernador de los departamentos de San Miguel y Concepción habiéndose originado de uno y otro un desorden universal de estos pueblos según se me han representado y no debiendo permitir su continuación le prevengo por segunda vez se abstenga de intervenir y mezclarse directamente ni indirectamente en el conocimiento de los bienes comunes de los dichos diecisiete pueblos a su cargo dejando libremente a sus administradores que los manejen con sujeción a las órdenes y métodos (Carta de Francisco de Paula Sanz al Sr. Gobernador de los Pueblos de Misiones, 1786, p. 2v). 
solicitó a los tres tenientes de gobierno departamentales, bajo jurisdicción de aquella intendencia, que le informaran con detalle las "utilidades o perjuicios que experimentan los naturales de los pueblos" en la compra de diferentes productos ya que "de algún tiempo a esta parte y sin intermediación alguna pasan a los pueblos de misiones diferentes comerciantes llevando facturas de ropas y otros efectos" (Informe solicitado por el superintendente general, Francisco de Paula Sanz, sobre la introducción de bebidas y efectos de comercio en los Pueblos de Misiones guaranies, 1788 y 1789, foja 1). En especial preocupaba el intercambio sin fiscalización, lo que implicaba la evasión impositiva, la introducción de bebidas no autorizadas, la adquisición de productos de forma particular, sin atener al precio y la calidad. Las respuestas al informe plasmaron las competencias por los recursos entre la administración de Buenos Aires, el gobernador de Misiones, los tenientes de gobernadores departamentales, los administradores de los pueblos y los corregidores guaraníes a través de acusaciones cruzadas entre los mismos. No obstante, también describieron las múltiples actividades y modalidades generadas en torno a la apertura comercial, a través de lo cual la agencia indígena, pese a su constante negación, fue indirectamente mencionada. ${ }^{20}$

Por su parte, las respuestas al informe solicitado por Sanz, sobre los potenciales perjuicios de la intensa presencia de comerciantes en los pueblos, fueron diversas y marcaron posicionamientos contrastados; estas representaron desde posturas radicales sobre el daño ocasionado, opiniones más conciliadoras, hasta la defensa absoluta de la adquisición de bienes por medio de comerciantes por su asociación con el bienestar de los pueblos. Las dos visiones antagónicas, la defensa de un mercantilismo controlado o de un mercantilismo abierto, estaban a su vez representadas por sujetos alineados, respectivamente, con una economía centralizada desde Buenos Aires en oposición a un gobierno misionero autónomo. En el primer grupo se encontraban los tenientes de gobernador de San Miguel y de Concepción, Manuel de Lasarte y Esquivel y Gonzalo de Doblas. Ambos departamentos estaban separados por el río Uruguay y sus pueblos estaban próximos a la frontera con los portugueses. Una postura intermedia, más conciliadora, fue expresada por el teniente de gobernador de Yapeyú, Pedro Castellanos, a cargo de los pueblos meridionales ubicados sobre los ríos Paraná y Uruguay y de las estancias que se extendían desde el río Uruguay en dirección hacia el Atlántico, poseedoras de gran riqueza ganadera. Por último, la defensa del libre ingreso de comerciantes a los pueblos la sostuvo, insistentemente, el gobernador de Misiones, Francisco Bruno de Zabala. El gobernador había iniciado su mandato en 1769 con jurisdicción sobre los 30 pueblos y tras esa concentración inicial se le fue quitando jurisdicción desde Buenos Aires para recortar su poder y fragmentar el mismo al interior del distrito misionero. ${ }^{21}$

\footnotetext{
${ }^{20}$ La alegación a la "incapacidad de los indios" fue el mecanismo de dominación que buscó obstruir el libre acceso de la población misionera al nuevo sistema mercantil en un contexto de liberación de las relaciones económicas.

${ }^{21}$ Tras la creación del virreinato su primer mandatario, Pedro de Ceballos, solicitó informes sobre el estado de los pueblos y así también lo hizo el gobernador de Buenos Aires, Juan José de Vértiz y Salcedo. Si bien los resultados de los mismos fueron alarmantes, las medidas más concretas apuntaron a recortar la jurisdicción y potestad al gobernador de Misiones, Francisco Bruno de Zabala, y el remplazo de los administradores denunciados de malversación por otros. En gran medida se buscaba desplazar a Zabala del control local que tenía sobre los asuntos económicos misioneros en una disputa que se originó con el entonces Administrador general en Buenos Aires, Juan Angel de Lascano. Zabala permaneció como gobernador de Misiones, con una potestad menor a la inicial, hasta su muerte en 1800 .
} 
Para defender sus posiciones, apelaron a asociaciones efectistas que dramatizaron los perjuicios o beneficios de la libre circulación de comerciantes en los pueblos. Si bien ninguno reconoció la venta de bebidas, aunque en la práctica se realizaba, los máximos detractores calificaron la venta de géneros a cambio de "frutos del país" como una "plaga y ruina". Desde la primera posición, Manuel de Lasarte y Esquivel, teniente de gobernador de San Miguel, insistió en que los perjuicios de la venta inadecuada de productos se evitarían "girándolos las comunidades a esta capital o a los parajes donde sus beneficios de ventajas" (Respuestas al "Informe" de Manuel de Lasarte y Esquivel, 1788, pp. 1v, 2 y 2v.). Al respecto, explicaba que "las comunidades de indios están exentas del importe de los derechos que pagan los españoles para sacar los productos de la capital" y que como "todo mercader tira la cuenta para las utilidades de su negociación es de menoscabo a las comunidades comprar a estos trajines especialmente cuando los géneros de ellos han pasado a segunda y terceras manos de unos pueblos a otros". A su vez, aclaraba que:

Aunque vengan con lo que puede ser de uso a los indios, traen al mismo tiempo cosas que le son ociosas y desaprovechables y muchas que miradas con la precisa consideración a la condición y situación de los pueblos son de lujo y profanidad que deben evitarse con debida consideración (Respuestas al "Informe" de Manuel de Lasarte y Esquivel, 1788, pp. 1v, 2 y 2v).

En función de lo cual remarcaba la necesidad de sostener "una estrecha, invariable sucesión de dependencias con responsabilidad de los corregidores, cabildos, administradores" (Respuestas al "Informe" de Manuel de Lasarte y Esquivel, 1788, p. 2v). La referencia a una sucesión de controles se trataba de una defensa argumentada siendo justamente los tenientes de gobernadores quienes debían supervisar el cumplimiento de los mismos. En la misma línea se ubicaba Gonzalo de Doblas, teniente de gobernador de Concepción, quien recordaba que "las ordenanzas establecen que los comerciantes deben entrar de febrero a abril pero han entrado y entran en todos los tiempos", esto "por más celo que se halla han de engañar a los indios les han de causar distracciones han de tener alianzas ilícitas". Por su parte, afirmaba que los comerciantes "se mantienen en la mayor parte a costa de los pueblos y por último a su retirada se llevan indios, muchachos y aún indias sacándolos de los pueblos para nunca volver a ellos" y proponía como solución "la prohibición absoluta de los comerciantes en estos pueblos con efectos, permitiéndoles solo los que traen ganado vacuno y caballar", así como que "los administradores no compren para el consumo de la comunidad de los que puedan venir de Buenos Aires". ${ }^{22}$

\footnotetext{
${ }^{22}$ Los bienes adquiridos más asiduamente eran cera, papel, aceite, vinagre, hierro, acero, herramientas, ponchos, gorros, pañuelos, calzones, lana, algodón, azúcar, miel, especias y sal (Respuestas al "Informe" de Gonzalo de Doblas, 1788, pp. 4 y 8v).
} 
Figura 1: Mapa de las reducciones guaraníes, año 1771

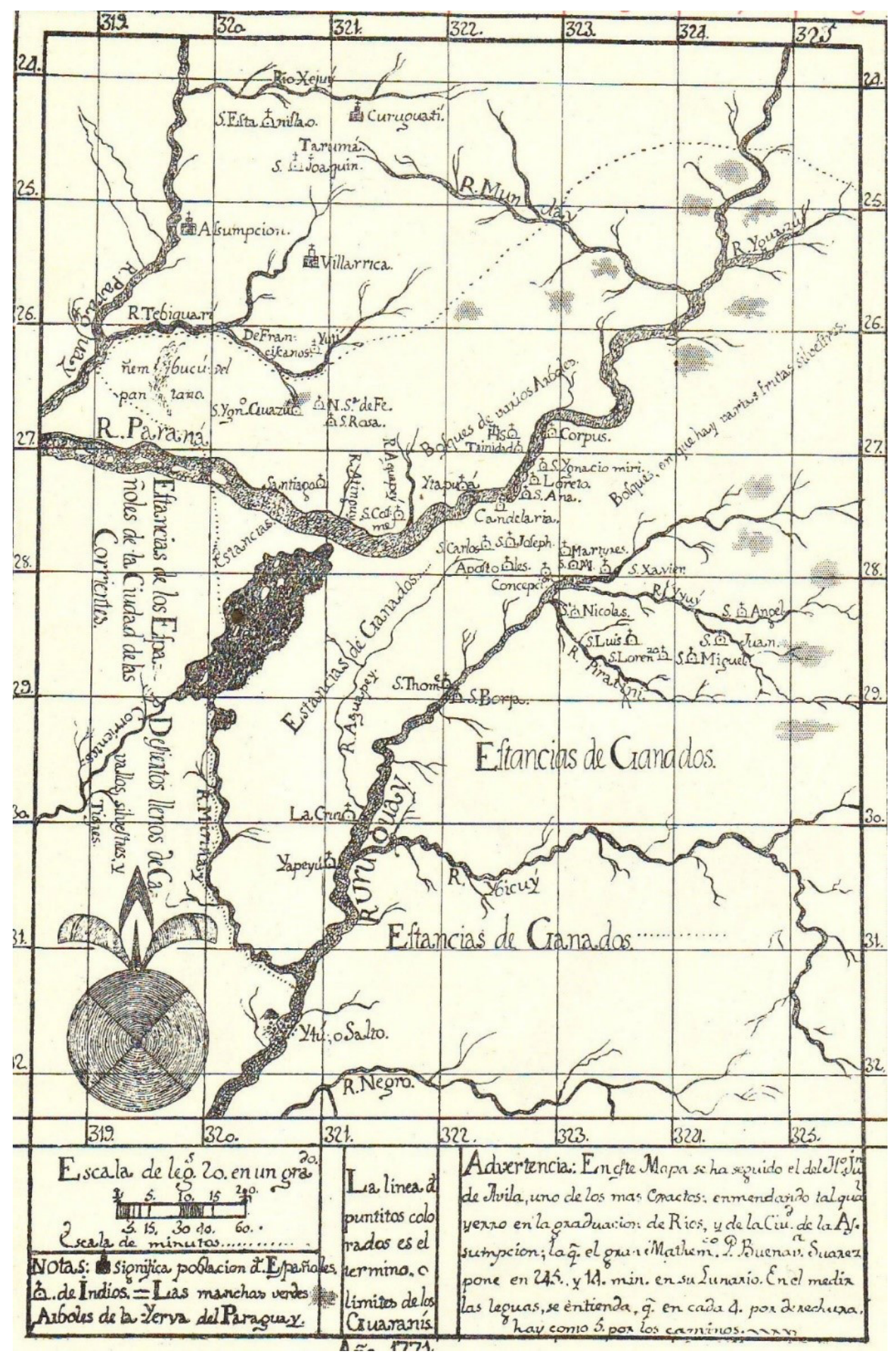

Fuente: Furlong (1936). 
En una postura intermedia, el teniente de gobernador de Yapeyú, Pedro Castellanos, afirmó que la venta se hacía con "equidad de precio a permuta de ganado y cueros resultantes de las reses que se matan para el consumo de la comunidad" y solo con su autorización (Respuestas al "Informe" de Pedro Castellanos, s.f., p. 3). Lo cual escondía prácticas de comercialización no fiscalizadas y sobre todo una falta de adecuación a los criterios de preservación y reproducción del ganado vacuno. Finalmente, el gobernador de Misiones, Francisco Bruno de Zabala, vinculó la adquisición de productos de comercio con "la felicidad y abundancia de dichos pueblos" y remarcó la "importancia del libre comercio" sin intermediaciones ya que:

Lo que se les trae a vender se estimularán estos naturales a aplicarle al trabajo y labranzas y sobre todo no faltarán los abastos y cuando sea la abundancia y abasto del País también sucederá lo que en los demás Reinos y entonces los que tengan forma aprovecharán la ocasión y las comunidades que nunca pueden estar a tiempo surtidas de todo lo que necesiten lograrán encontrar con mejor partido modo de proveerse porque los pueblos no tiene sobrantes para formar almacenes de repuesto general a que se agrega los transportes y demás que deban pagar los comerciantes y sus dependientes quedan en los pueblos y entre sus vecinos salvándoles del riesgo cuanto no quieran exponerse libertándoles de las demoras y gastos de conducciones logrando el trato de los españoles para cuyo medio hay muchos indios adelantados, seguirán las alianzas y sagrados vínculos que he amparado porque son los medios de que comprendan que son tratados sin ninguna diferencia como todos los demás vasallos de Su Majestad (Carta de Francisco Bruno de Zabala al virrey Nicolás de Arredondo, 1790, p. 16).

Zabala conocía la dinámica regional y la intimidad de los intercambios desde la región misionera con más profundidad que muchos otros funcionarios que hacía poco tiempo habían llegado a América. ${ }^{23}$ También disponía de información sobre las complejidades implicadas y las prácticas derivadas de las transacciones mercantiles como era el tema de los transportes fluviales, para los cuales se recargaba a la población misionera, se deterioraban las embarcaciones, se incrementaban los costos y se demoraba la llegada de productos. Sin embargo, sus argumentaciones escondían intereses particulares, ya que su insistencia en la libertad de intercambio con los comerciantes, la cual definía como "sagrados vínculos", respondía a tratos que él tenía con ellos (Hernández, 1999; Maeder, 1992). Este hecho sumado a la ideología de "asimilar" a los indígenas a la sociedad colonial como supuesto acto de igualdad cobraba otra dimensión al reparar en las acusaciones mutuas. $\mathrm{Al}$ respecto, Doblas en sus alegaciones se refirió al manejo del comercio entre administradores y comerciantes, en términos de "monipodio", consolidado al amparo del gobernador Zabala y sostuvo, junto a Lasarte y Esquivel, la importancia de la Administración General a los fines de controlar la circulación mercantil en las misiones. En su defensa, los administradores de los pueblos, también consultados, señalaron a los corregidores guaraníes como los principales agentes de

${ }^{23}$ Francisco Bruno de Zabala era hijo del español Bruno Mauricio de Zabala, gobernador de Buenos Aires (1717-1734). Había participado de las tropas españolas que integraron la Expedición de Límites (1753) conformada para poner en práctica el Tratado de Madrid (1750), así como del ejército armado contra la resistencia de los pueblos y los jesuitas a dejar siete de sus reducciones por las consignas del Tratado. Por último, había estado entre los capitanes y soldados que ocuparon los pueblos orientales, por varios años, tras la batalla de Caybaté (Bruno, 1991; Maeder, 1992; Quarleri, 2009). 
ese intercambio. ${ }^{24}$ Por su parte, Zabala enfrentado con la Administración General, había sido previamente interpelado primero por el gobernador intendente de Buenos Aires, Francisco de Paula Sanz y más tarde por el Virrey Arredondo por no haber:

Evacuado aún el referido informe sin embargo del tiempo que ha ocurrido desde que lo ofreció me ha parecido recordárselo previéndole al mismo tiempo me diga con toda claridad y fundamento si es o no conveniente al beneficio de los pueblos la introducción en ellos de género y efectos de comercio que se hayan prohibido por esta superintendencia (Carta de Nicolás Arredondo al gobernador de Misiones, 1790, p. 12v.).

Tras la intimación del virrey, Zabala realizó una extensa respuesta, en la que incluyó a Gonzalo de Doblas en una disputa que trascendía la discusión sobre el bienestar de la población misionera, insistiendo en:

La importancia del libre comercio y que los intereses particulares que mueven a ponderar los perjuicios que con buena intención y para obligación se puede evitar y contener si hubiese la buena unión y subordinación que es necesario haya de parte de los tenientes de gobernador y que estos se abstengan de ejecutar lo que Gonzalo de Doblas que se ha ligado en compras y ventas de negociación según consta de la sumaria averiguación secreta que por orden superior la formé y la remití en original (Carta de Francisco Bruno de Zabala al virrey Nicolás de Arredondo, 1790, p. 15).

Asimismo, justificaba las demoras como la ingobernabilidad del territorio por el quiebre en el sistema de obediencias y por la falta de colaboradores, alegando la necesidad de contar con "un asesor, un secretario, un teniente protector de naturales y que estos son indios con que tengo mucho trabajo (Carta de Francisco Bruno de Zabala al virrey Nicolás de Arredondo, 1790, p. 15). Tanto la expoliación de los bienes comunales por afanes sectoriales como el control de la circulación de productos desde la capital virreinal, expresaban una presencia sustantiva del poder político sobre los intercambios mercantiles de forma similar a los repartos forzosos de mercancías impuestos en pueblos de indios de zonas centrales de los virreinatos hispanoamericanos. De esta forma, el modelo de intervencionismo mercantil en las misiones representó una de las tantas contradicciones del proyecto modernizador del reformismo borbónico, ya que basado en la apertura comercial mantuvo sistemas de coacción política, económicas y punitivas para dinamizar el mercado interno, generar beneficios sectoriales, sostener la burocracia y sumar al erario real. ${ }^{25}$ Por su parte, la expansión mercantil generó alianzas comerciales entre autoridades étnicas, funcionarios españoles y mercaderes que provocaron cambios en las dinámicas de reproducción comunal, junto con la incorporación de nuevos consumos y modalidades de participación en los circuitos comerciales.

\footnotetext{
${ }^{24}$ Pedro Fontela, administrador del pueblo de Concepción, en las respuestas al informe solicitado dijo que si "los naturales" tenían "trato con los comerciantes" era sin su consentimiento y que el "primer contraventor en esta materia es el corregidor" (Respuestas al "Informe" del administrador Pedro Fontela, 1788, p. 8).

${ }^{25}$ En este sentido, tal como lo expresa Guillermo Madrazo "la prioridad asignada a los objetivos económicos de la metrópoli implicó que el proyecto modernizador se emprendiera con un 'saldo político y social de dudoso signo"' especialmente en relación con los pueblos de indios (Madrazo, 2005, p. 30).
} 


\section{Reapropiaciones, lógicas diferenciales y agencia indígena}

Una de las paradojas del nuevo modelo económico fue la puesta en práctica de un comercio libre pero vinculado a las necesidades de mantenimiento de la burocracia administrativa creada para comerciar con los pueblos. Esta circularidad respondía a la intención de apropiarse de la energía, bienes y tierras de uno de los complejos productivos y humanos más importantes de la región. Por su parte, las reglamentaciones elaboradas para ordenar el intercambio comercial solo actuaron como marco referencial de legalidad en la instancia discursiva. La adaptación permanente, alegando diferencias entre uno u otro pueblo así como el estado de pobreza de los mismos, su falta de provisión, los altos costos, las desobediencias, complicidades y monopolios, conformó la estructura sobre la que se construyó la cotidianidad política y económica en los informes solicitados.

Por otra parte, si bien la comercialización de los bienes estuvo acompañada de documentación oficial donde se remarcó en ideas asociadas a la "regularización del consumo", "tasación”, "previsión”, “conveniencia”, "justicia”, "ecuanimidad", "orden y "equidad" su reiteración, sin un cambio de política, expresó incongruencias entre las bases ideológicas y las dinámicas económicas resultantes. Esta situación también dio cuenta de la reproducción de una modalidad de dominio construido sobre el desfasaje entre discurso proteccionista y resortes gubernamentales instituidos para el cuidado de la población y sus recursos. El modelo, aunque preveía modalidades de fiscalización de los movimientos mercantiles, estableciendo registros contables, períodos, tipos de vías y trasportes, selección de bienes comercializables por pueblo y evaluación de la calidad de los bienes a adquirir, no conllevó la incorporación de una visión integral. Dos décadas después de la implementación del sistema, Gonzalo de Doblas afirmó que no había en los intercambios, consumos y abastecimientos misioneros "ni regla, ni economía" (Respuestas al "Informe" de Gonzalo de Doblas, 1788, p. 4).

Uno de los aspectos que se desprende es el contraste entre modalidades e ideales culturales de consumo que enfrentó desde la óptica borbónica: racionalidad con descontrol. Desde los primeros informes realizados se consignaron observaciones en relación con que los guaraníes "gastaban" sus recursos hasta "que se les acaba". No obstante, las lógicas de acopio en los almacenes y distribución respondían a políticas que los jesuitas habían implementado sobre las prácticas de consumo preeminentes entre las parcialidades guaraníes reducidas. Los jesuitas en sus crónicas repararon en las discrepancias mencionadas y en la implementación de un sistema de entregas diarias de raciones, en especial de carne vacuna y ropa, como medio para sostener la presencia cotidiana en los pueblos. Esta práctica continuó tras la expulsión en los días festivos y durante las "faenas" como una política transitoria. El objetivo era reemplazarla por el incentivo a la productividad familiar y por los efectos derivados del propio impulso comercial. Sin embargo, la ecuación no se vislumbró en la práctica y las raciones como referente de acceso a bienes básicos no fueron sustituidas. El problema fue que el ganado y otros bienes empezaron a mermar y las raciones fueron cada vez más escasas generando crisis alimentaria. A ello se agregó la falta de producción local de algodón para la confección de ropa y el deterioro paulatino de las viviendas.

$\mathrm{Al}$ no disponer de moneda acuñada, el algodón se constituyó desde tiempos jesuitas en el principal medio de cambio como así también de pago de salarios y prebendas. Esto generó mayores presiones laborales en el periodo posterior a la expulsión, 
en particular sobre las mujeres, vinculadas desde el origen de las reducciones a las obligaciones de hilado, que se expresó en el aumento de las cargas semanales por la propia decisión de los administradores y tenientes de gobernadores. La falta de algodón como la imposición de obligaciones alteró la capacidad de reproducción. En un informe realizado tras su visita a varios pueblos el gobernador de Misiones Francisco Bruno Zabala observó que:

Las indias por razón de las tres tareas de hilanza que se les dan cada semana no tienen tiempo para hacer algún hilo para vestirse ella y sus hijos, tampoco para ayudar a sus maridos en sus chacras, las cuales quedan abandonadas cuando van ellos a los trabajos del pueblo, y no tienen para alimentarse suficientemente (Visita a San Apóstoles de Francisco Bruno de Zabala, capitán de Regimiento de Dragones de Buenos Aires y gobernador de los Treinta Pueblos, de 1787, p. 3).

Estas imputaciones cristalizaban la crisis del sistema económico misionero así como el menoscabo manifestado por los "maridos" sobre los derechos al trabajo de sus mujeres, incluso de mujeres de caciques, en una relación de sujeción y dominación de género donde se yuxtapusieron tradiciones prehispánicas como matrices occidentales de vertiente jesuítica y colonial ibérica. ${ }^{26}$ La crisis de abastecimiento por falta de producción, inversión y malversación se profundizó, a su vez, como consecuencia de las incongruencias derivadas de las prácticas mercantiles realizadas por los funcionarios hispanos. ${ }^{27}$ Una de ellas consistió en la compra de listones, ponchos y gorros a cambio de toros y bueyes y la compra posterior de estos últimos "con urgencia y mal precio" argumentando ser fundamentales para el trabajo de la tierra (Respuestas al "Informe" del administrador Pedro Fontela, 1788, p. 8). El algodón, por su parte, se obtenía a cambio de yerba generando mayores presiones sobre el trabajo indígena en los yerbales, especialmente en los pueblos de la Intendencia de Paraguay. De esta forma se pasó a comprar productos, que antes se producían internamente, a comerciantes que venían a los pueblos a cambio de bienes de comunidad que luego irían a necesitar. ${ }^{28}$

La producción de bienes en los trigales, yerbales o en las tareas de hilado se estructuró a través de un sistema punitivo, basado en el castigo físico. En este contexto, en enero de 1788, el cacique del pueblo guaraní de San Lorenzo denunció ante las autoridades hispanas del complejo misionero que María Irapayu, su mujer, había sido "azotada en las nalgas" como forma de castigo por orden del corregidor indígena, tras haber faltado un día a la cosecha de trigo que debía realizarse como parte de las obligaciones comunales (Provisión del teniente de gobernador de este Departamento de San Miguel, Don Manuel de Lasarte y Esquivel, por la queja dada por el cacique Don Agustín Guairaye, pueblo de la Real Corona titulado San Nicolás de Bari, 1788). El teniente de gobernador, enemistado

\footnotetext{
${ }^{26}$ Una primera aproximación a esta problemática fue presentada en la ponencia "Violencia física y control de los cuerpos: trabajo, género y poder en pueblos indígenas fronterizos de fines del siglo XVIII" (Quarleri, 2017).

${ }^{27}$ Cabe aclarar que los administradores que respondieron al informe solicitado por el gobernador intendente Francisco de Paula Sanz (Pedro Nolasco Alfaro de San Carlos, Francisco Martínez Lobato de San José, Miguel de Pereyra de Apóstoles, Thomas Gómez de Santos Mártires, Pedro Antonio Nieto de San Javier, Domingo Bermúdez de Santa María La Mayor, Pedro Fontela de Concepción) en la mayoría de los casos reconocieron que los comerciantes les vendían productos a los guaraníes de forma particular pero que lo hacían sin que ellos lo supieran.

${ }^{28}$ Zabala afirmaba que lo que más escaseaba era el algodón "pudiéndolo tener de sus cosechas" (Visita a San Nicolás de Francisco Bruno de Zabala, capitán de Regimiento de Dragones de Buenos Aires y gobernador de los Treinta Pueblos, 1787, p. 3).
} 
con el corregidor de esa reducción y del gobernador de las treinta misiones levantó otros testimonios que daban cuenta que otras mujeres también habían sido azotadas como forma de escarmiento por ausentarse a la cosecha de maíz. Este no fue un caso aislado. Por el contrario, las denuncias fueron permanentes generando un corpus documental extenso, tras lo cual se planteó la "necesidad" de regular el castigo, marcando una tipología de prácticas punibles a través del encarcelamiento y los azotes, instituyendo marcos de acción legitimados que no hacían más que naturalizar la violencia física como medio disciplinante a los fines del modelo productivo. ${ }^{29}$

Dentro de este contexto, la "huída" de los pueblos fue una de las respuestas más contundentes frente a la coacción vivida. No obstante, como las "fugas" eran penadas y castigadas, la resistencia también se expresó estratégicamente desde la acción cotidiana y en especial en la esfera del trabajo y el comercio. Esto se manifestó, en parte, a través de la reapropiación de ciertas prácticas de intercambio y acceso a bienes que invirtieron y desplazaron los objetivos implícitos de la política económica plasmada por Bucarelli en sus ordenanzas. ${ }^{30} \mathrm{Al}$ respecto, mientras que esta política estaba sustentada en la negación de la capacidad indígena para intervenir en los tratos comerciales con mercaderes u otros agentes en el espacio misionero, la participación indígena se canalizó rechazando ciertos esquemas asociados a la productividad familiar, al trabajo coactivo y abusivo, por medio de la generación de prácticas mercantiles propias. Uno de los principales ejes resistidos fue el de la "racionalidad" económica occidental por el acopio y distribución del consumo. ${ }^{31}$ Si bien esta oposición se evidenció en relación con las viejas prácticas de los jesuitas, basadas en el acopio y la distribución, con la nueva política económica mercantil borbónica se hizo más evidente aún al estar esta última proyectada sobre los beneficios de la compra y venta de productos en contraste con la entrega de raciones diarias.

Otro aspecto combatido fue el control sobre el acceso a las vaquerías, el consumo de ganado y la comercialización de reses y cueros desde la administración general o desde el gobierno local, en particular en aquellos pueblos estancieros como Yapeyú o San Miguel. ${ }^{32}$ De forma abierta, el rechazo a las injerencias de los

\footnotetext{
${ }^{29}$ A través de una real cédula de 1778 se consignaba que "en los castigos por faltas y yerros que cometiesen los indios en lo relativo a haciendas, trabajos del pueblo y construcción de chacras no tuviesen más intervención que noticiarlos al corregidor y al cabildo pidiendo remedio con el castigo moderado" (Reglas para el mejor gobierno de los guaraníes, 1788, p. 4v.).

${ }^{30}$ Julia Sarreal en su libro sobre la economía misionera infiere a partir del análisis de documentación económica que a partir de la década de 1780 la adquisición de bienes de forma particular para el consumo diario adquirió protagonismo sobre la producción en tierras comunales. Entre las prácticas de acceso a bienes alimentarios la caza de ganado salvaje se encontró entre sus opciones, así como la recolección de yerba silvestre sobre las plantaciones domésticas al mismo tiempo que se manifestó un declive en el cultivo de algodón ampliamente resistido por los guaraníes (Sarreal, 2014).

${ }^{31}$ Las ideas en torno al bienestar, el uso del tiempo, el intercambio y el consumo fueron un tema de tensión desde los tiempos jesuíticos. Lo mismo ocurrió con los intercambios de bienes, ya que si bien estos eran supervisados por los jesuitas no faltaban los casos en los que los guaraníes trocaban productos en la campaña con sus vecinos los charrúas, los guenoas o los portugueses, con objetivos diversos (Catafesto, 2002; Meliá y Temple, 2004; Quarleri, 2013).

32 Erich Edgard Poetniz, en un trabajo publicado en 1983, analiza con minuciosidad la economía de Yapeyú, pueblo que tenía la reserva ganadera más importante de todo el complejo misionero. Al reparar en los cambios suscitados en el periodo post-jesuita, el autor afirma que si bien en las primeros tiempos Yapeyú proveyó de ingresos que satisfacían a la administración general de Buenos Aires, a partir de 1784 los envíos disminuyeron en la medida que se prefirió negociar directamente con comerciantes que concurrían desde Paraguay (Poetniz, 1983).
} 
funcionarios borbónicos sobre los recursos ganaderos se había manifestado, en 1778, en el conocido "Motín de Yapeyú". ${ }^{33}$ Por su parte, el contrabando de ganado fue el principal contrapunto del ideal de comercio soslayado por la administración borbónica desde Buenos Aires puesto que se constituía en la principal riqueza del espacio rioplatense y el bien más preciado de los intercambios mercantiles (Caletti, 2015; Moraes, 2007).

El "comercio clandestino", como lo denominaban las autoridades hispanas, fue el enemigo del "comercio ilustrado" diagramado sobre la apertura de los tratos a las provincias circunvecinas controlados desde la capital virreinal. El mismo se instituyó en el caso de las misiones jesuíticas como un comercio de varias fronteras en virtud de los diversos pasos existentes y puertos, así como por la cercanía con los fuertes y puestos portugueses y por el poblamiento multiétnico circundante. Su realización se hacía a costa de "los ganados mayores que sirven a su conservación y fomento" para vender cueros, grasas y cebos (Carta del Virrey marques de Loreto a Francisco Bruno de Zabala, 1788, p. 11v). La base de este asiduo comercio lo constituía la coyuntura de demanda tanto local como transatlántica de cueros. Este comercio se hacía también con ganado caballar de las reservas de las estancias de cada pueblo como sobre las de otros. ${ }^{34}$ Las estancias de los pueblos australes serán, especialmente, objeto de litigios con colonos criollos que irán ocupando tierras sobre franjas linderas, y también de continuos saqueos de ganado que tanto infieles como guaraníes "fugados" realizaban para luego venderlos a los portugueses.

Sin embargo, el tema central que preocupaba a la Administración general y que había instado a la elaboración del informe por parte de Sanz era que, pese a todas las especulaciones y sistemas de controles, los comerciantes ingresaban a los pueblos, en diferentes épocas y trataban directamente con la población, en algunas reducciones eran más comunes las adquisiciones particulares que en otras. Esto estaba relacionado con la ubicación, siendo algunas de tránsito y otras distantes, con la postura tomada por administradores y corregidores, así como con la disposición de excedentes para el trueque provenientes principalmente de chacras familiares. Los comerciantes solían entregar productos a cuenta, generando deudas futuras, o lo hacían a cambio de diversos trabajos que garantizaban su permanencia en los pueblos o también de ganado, cueros, yerba y lienzos. En su defensa, los administradores alegaron desconocer el momento en que se hacían los intercambios. ${ }^{35}$ También insistieron en la dificultad de controlar las adquisiciones particulares arguyendo que estas eran

\footnotetext{
${ }^{33}$ En noviembre de 1778, el teniente de gobernador de Yapeyú Juan de San Martín, dispuso la realización de una vaquería para traer ganado cimarrón a las estancias misioneras. El encargado de ella, el cacique y alcalde de segundo voto, Melchor Aberá no realizó la misma y fue encarcelado, a lo que se respondió con un levantamiento de varios caciques tras lo cual intervino el virrey Vértiz (Hernández, 1999).

${ }^{34}$ Manuel de Lasarte y Esquivel afirmó que algunos indios naturales de San Juan y San Nicolás han sido acusados de robar caballos de la estancia de San Nicolás para llevarlos al puerto de San Juan y de ahí a la estancia de San Borja. Desde este pueblo comerciaban con los portugueses de Río Pardo (Carta del teniente de gobernador Manuel de Lasarte y Esquivel a Francisco de Paula Sanz, 1788, p. 11v.).

${ }^{35}$ Era "costumbre antigua en estos sobre las ventas que hacen a los particulares del pueblo por más que repetidas veces les tenga advertido me den parte" (Respuestas al "Informe" del administrador Miguel de Pereyra, 1788, p. 7).
} 
realizadas a sus espaldas. ${ }^{36}$ Esta argumentación fue reiterada por el administrador de Concepción. Él mismo afirmó que "si los naturales han tenido trato con los comerciantes es sin que el administrador lo sepa pese a que se los ha hecho saber por medio de lenguzetas en su idioma" (Respuestas al "Informe" del administrador Pedro Fontela, 1788, p. 8v.). En términos generales, se instituyó la idea de que las compras se realizaban a escondidas para desviar la atención sobre las sospechas que recaían en los administradores y corregidores indígenas, al mismo tiempo que se confirmó su existencia.

Desde otra esfera, el teniente de gobernador del departamento de Concepción, Gonzalo de Doblas, reconoció que los guaraníes de forma particular realizaban permanentemente tratos comerciales pero remarcando que ocultaban las compras "sin que pueda comprender cuál sea la causa si ya no es el que todos aparentan más pobreza de lo que en realidad tienen para que así lo socorra la comunidad" ("Informe" de Gonzalo de Doblas, 1788, p. 4). En contraposición, Zabala defendió la compra de bienes por vía individual y afirmaba que "si compran a escondidas no es para ocultar pobreza y ser proveídos por los almacenes, porque este está para las mayores necesidades". Para el gobernador, las compras estaban ligadas a un "deseo natural de adquirir" que aunque cuestionable daba cuenta de que las compras de bienes se hacían con independencia del control político, por decisiones particulares y en virtud de necesidades desencadenas tras la pérdida de capacidad de reproducción comunal, así como por las nuevas concepciones sobre el consumo y el valor de ciertos bienes (Carta de Francisco Bruno de Zabala al virrey Nicolás de Arredondo, 1790, p. 16v).

Estos nuevos consumos, además de responder a una penetración colonial dada en gran medida por la convivencia interétnica, abrió una brecha, al interior de los pueblos, entre aquellos "indios más castellanos" y aquellos otros que no habían adoptado nuevos "usos y costumbres" en ese línea. Hacia fines del siglo xviri, la administración colonial reparó entre quienes sabían "tratar y contratar", hablaban el castellano y habían incorporado otras costumbres europeas, como el uso de determinada ropa. Una parte de estos últimos, previa intermediación de administradores y curas de los pueblos, pasaron a ser liberados de las cargas comunales, siguiendo el decreto del Virrey Aviles de 1800 (Nominas de naturales propuestos para libertad, elaboradas por administradores y curas de los pueblos, 1799 y 1800).

\section{Palabras finales}

Al indagar sobre las bases ideológicas del modelo de intervención borbónica en la economía misionera a partir de las instrucciones del gobernador Bucarelli, nos encontramos con extensas argumentaciones sobre los utópicos beneficios del libre comercio entre estados, provincias y pueblos; concepciones propias de la época

\footnotetext{
36 "Sin hubiera cosas que los indios necesitarían también comprarían con sus frutos (...) sin que el administrador los pueda remediar porque ellos lo ocultan y sin embargo que pondré todo el cuidado posible en evitar estos contratos (...) dudo poder evitarlos" (Respuestas al "Informe" del administrador Pedro Nolasco Alfaro, 1788, p. 6v).
} 
que Bucarelli más allá de su afinidad con las reformas ilustradas, lideradas por el Virrey Amat, dejó claramente plasmadas para ser aplicadas en las reducciones pero con la enorme paradoja de que la libertad económica no podía concederse sin intermediaciones a los pueblos de indios guaraníes. Sin embargo, analizada en un contexto mayor, la apertura del comercio con los pueblos de misiones no fue solo el resultado de las idealizadas proyecciones manifestadas por Bucarelli en sus ordenanzas; por el contrario, la misma fue producto de la convergencia de múltiples factores. Uno de ellos fue la propia dinámica que se venía gestando, antes de la expulsión de los jesuitas, en torno a la expansión poblacional en los contornos misioneros, producto de un aumento demográfico como de una creciente demanda de recursos ganaderos. Otro de los elementos de peso fue el interés real por los beneficios derivados de la concentración de recursos y mano de obra, a través de su circulación dentro del mercado interno, como de la retención impositiva asociadas. Entre otras cuestiones, influyó también el giro asimilacionista del colonialismo reformista de la época sopesado ante la evaluación de que la política segregacionista, desplegada por las monarquías y dinastías predecesoras, no solo entraba en conflicto con los nuevos paradigmas modernizadores, sino que había mostrado su inoperancia. Finalmente, motivó la coyuntura mercantilista sobre la que se alimentó una contradictoria narrativa en torno al sublime imperio del comercio en su variante colonialista sobre la que se enfrentaron los intereses sectoriales de diferentes actores en juego.

El modelo mercantilista en las misiones no solo se enfrentaría con las reapropiaciones, rechazos y derivaciones realizadas por los propios guaraníes, sino también con las interpretaciones y adaptaciones a sus propios intereses llevadas a cabo por los propios funcionarios en sus jurisdicciones locales y virreinales. Desde diferentes frentes, se buscaba acceder a los productos agrícolas, ganados, cueros y bienes manufacturados antes monopolizados por los jesuitas y abrir el juego a las provincias vecinas de Asunción, Corrientes, Buenos Aires y Santa Fe. Sin embargo, Buenos Aires, como flamante sede virreinal, pretendió direccionar las lógicas de los beneficios regionales con una intervención inusitada. Desde el ámbito misionero, las lógicas de apropiación también se reprodujeron. Así, si bien, desde los departamentos misioneros — que caían bajo jurisdicción de la Intendencia de Buenos Aires- se argumentaron, por estrategia o por convicción, las desventajas aparejadas por el trato directo de los guaraníes con los comerciantes, el gobernador de misiones con mayor trayectoria en el espacio rioplatense y con una dimensión más regionalista del tema, frente a Buenos Aires, defendió la libertad de los contratos y la penetración sin restricciones de mercaderes vecinos en las reducciones.

Desde ambas posturas, por un lado, negando la capacidad indígena para intervenir en los tratos comerciales con mercaderes u otros agentes en el espacio misionero y, por otro lado, avalándola abiertamente por sus vínculos con los mercaderes de las jurisdicciones vecinas, la participación indígena se expresó finalmente en sus propios términos. De forma general, se canalizó rechazando ciertos esquemas asociados a la productividad familiar, al trabajo coactivo y abusivo y por medio de la generación de prácticas mercantiles propias. Uno de los principales ejes resistidos fue el de la "racionalidad" económica occidental por el acopio, consumo y producción comunal de ciertos cultivos. Primando las decisiones particulares. Otra forma de expresar su rechazo a los lineamientos fiscalizadores fue el "comercio clandestino", principal enemigo del "comercio ilustrado". En suma, la adaptación a estructuras y vínculos nuevos, la resistencia a viejas y nuevas prácticas, las respuestas particulares 
o familiares dentro de un progresivo desmembramiento de las cohesiones cacicales, el aprovechamiento de circuitos mercantiles de carácter multiétnico, como era la comercialización de ganado, se hicieron cada más evidentes frente a los límites desdibujados de un poder colonial fragmentado.

\section{Referencias}

Benjamin, W. (1982). Discursos interrumpidos I. Madrid, España: Taurus.

Bravo, J. (1872). Colección de documentos relativos a la expulsión de los jesuitas de la República Argentina y del Paraguay, en el Reinado de Carlos III. Madrid, España: Establecimiento Tipográfico de José María Pérez.

Bruno, C. (1991). Las reducciones jesuíticas de indios guaranies (1609-1818). Rosario, Argentina: Ediciones Didascalia.

Caletti, B. (2015). Milicias y guaraníes en Yapeyú. La defensa de la "frontera del Uruguay" en los albores del siglo xix. Prohistoria, (23), 47-70.

Carta de Francisco Bruno de Zabala al virrey Nicolás de Arredondo. (13 de marzo de 1790). (Sala Ix, Legajo 17-8-6, sin número de documento, foja 16). Archivo General de la Nación, Candelaria, Argentina.

Carta de Francisco de Paula Bucarelli y Ursúa al señor conde de Aranda. (14 de octubre de 1768). Colección Biblioteca Nacional (Sala viI, Legajo 255, Documento 3634, foja 10v.). Archivo General de la Nación, Buenos Aires, Argentina.

Carta de Francisco de Paula Sanz al Sr. Gobernador de los pueblos de misiones. (13 de diciembre de 1786). (Sala Ix, Legajo 17-8-6, sin número de documento, foja 2v.). Archivo General de la Nación, Buenos Aires, Argentina.

Carta de Nicolás Arredondo al gobernador de Misiones. (Enero de 1790). División colonia. Sección Gobierno (Legajo 17-8-6, sin número de documento, foja 12v). Archivo General de la Nación, Buenos Aires, Argentina.

Carta del teniente de gobernador Manuel de Lasarte y Esquivel a Francisco de Paula Sanz. (21 de abril de 1788). (Sala Ix, Legajo 17-8-6, sin número de documento, foja 11v.). Archivo General de la Nación, San Luis, Argentina.

Carta del Virrey marques de Loreto a Francisco Bruno de Zabala. (15 de diciembre de 1788). (Sala Ix, Legajo 17-8-6, sin número de documento, foja 11v.). Archivo General de la Nación, Buenos Aires, Argentina.

Catafesto, J. O. (2002). O sistema econômico nas sociedades indígenas guarani pré-coloniais. Horizontes Antropológicos, 8(18), 211-253.

Cavieres, E. (2011). Mercados y comercio informal en el Chile de la transición de colonia a república. Nuevo Mundo, Mundos Nuevos, Débats. Recuperado de https:// nuevomundo.revues.org/60545

Furlong, G. (1936). Cartografía jesuita del Río de la Plata (núm. LXxi). Buenos Aires, Argentina: Talleres S.A., Casa Jacobo Peuser.

Haubert, M. (1991). La vida cotidiana de los indios y jesuitas en las misiones del Paraguay. Madrid, España: Editorial Temas de Hoy.

Hernández, J. (1999). Tumultos y motines. La conflictividad social en los pueblos guaraníes de la región misionera (1768-1799). Memoria Americana, (8), 83-100. 
"Informe" de Gonzalo de Doblas. (5 de septiembre de 1788). (Sala Ix, Legajo 17-8-6, sin número de documento, foja 4). Archivo General de la Nación, Pueblo de Concepción, Argentina.

Informe solicitado por el superintendente general, Francisco de Paula Sanz, sobre la introducción de bebidas y efectos de comercio en los Pueblos de Misiones guaranies. (1788 y 1789). (Sala Ix, Legajo 17-8-6, sin número de documento). Archivo General de la Nación, Buenos Aires, Argentina.

Lucena, M. (1996). El reformismo de frontera. En A. Guimerá (Coord.), El reformismo borbónico (pp. 265-292). Madrid, España: Alianza Editorial.

Madrazo, G. (2005). Pacto étnico, rebelión y modernidad en el siglo xviII. Andes, 16, $27-44$.

Maeder, E. (1987). El modelo portugués y las instrucciones de Bucarelli para las misiones de guaraníes. Estudos Ibero-Américanos, XIII(2), 135-150.

Maeder, E. (1992). Misiones del Paraguay, conflicto y disolución de la sociedad guaraní(17681850). Madrid, España: Mapfre.

Meliá, B. y Temple, D. (2004). El don, la venganza y otras formas de economía guaraní. Asunción, Paraguay: Centros de Estudios Paraguayos "Antonio Guasch".

Moraes, M. I. (2007). Crecimiento del Litoral rioplatense colonial y decadencia de la economía misionera: un análisis desde la ganadería. Investigaciones de Historia Económica, (9), 11-44.

Nominas de naturales propuestos para libertad, elaboradas por administradores y curas de los pueblos. (1799 y 1800). (Sala Ix, Legajo 18.3.1). Archivo General de la Nación, Buenos Aires, Argentina.

Ortelli, S. (2011). Introducción al dossier: La participación indígena en los mercados iberoamericanos. De la colonia a los primeros años independientes. Nuevo Mundo, Mundos Nuevos, Débats. Recuperado de https://nuevomundo.revues. org/60764

Palomeque, S. y Jumar, F. (2007). Dossier Participación indígena y circuitos mercantiles en los espacios coloniales españoles y sus fronteras. Anuario del IEHS, (21).

Poetniz, E. E. (1983). La economía del Yapeyú postjesuítico. Actas de IV Encuentro de Geohistoria Regional. Resistencia, Argentina: Instituto de Investigaciones Geohistóricas, Conicet.

Poetniz, E. E. y Poetniz, A. (1998). Misiones, provincia guaranítica: defensa y disolución (1768-1830). Posadas, Argentina: Universitaria.

Provisión del teniente de gobernador de este Departamento de San Miguel, Don Manuel de Lasarte y Esquivel, por la queja dada por el cacique Don Agustín Guairaye, pueblo de la Real Corona titulado San Nicolás de Bari. (18 de enero de 1788). (Legajo 17-8-4, sin número de documento). Archivo General de la Nación, Misiones, Argentina.

Quarleri, L. (2009). Rebelión y guerra en las fronteras del Plata. Guaranies, Jesuitas e Imperios coloniales. Buenos Aires, Argentina: Fondo de Cultura Económica.

Quarleri, L. (2013). Lógicas y concepciones sobre trabajo, acumulación y bienestar en los pueblos guaraníes (Siglos XVII-XVIII). Revista anOS 90, 20(37), 177-212.

Quarleri, L. (julio de 2017). Violencia física y control de los cuerpos: trabajo, género y poder en pueblos indigenas fronterizos de fines del siglo XVIII. Trabajo presentado en XIII Jornadas Nacionales de Historia de las Mujeres. Horizontes Revolucionarios. Voces y Cuerpos en Conflicto, Buenos Aires, Argentina. 
Reglas para el mejor gobierno de los guaranies. (1788). Colección Biblioteca Nacional (Sala VII, Legajo 310, Documento 5065, foja 4v). Archivo General de la Nación, Buenos Aires, Argentina.

Respuestas al "Informe" de Gonzalo de Doblas. (5 de septiembre de 1788). (Sala Ix, Legajo 17-8-6, sin número de documento, fojas 4 y 8v.). Archivo General de la Nación, Pueblo de Concepción, Argentina.

Respuestas al "Informe" de Manuel de Lasarte y Esquivel. (5 de septiembre de1788). (Sala Ix. Legajo 17-8-6, sin número de documento, fojas 1v, 2 y 2v.). Archivo General de la Nación, San Nicolás, Argentina.

Respuestas al "Informe" de Pedro Castellanos. (s.f.). (Sala Ix, Legajo 17-8-6, sin número de documento, foja 3). Archivo General de la Nación, Buenos Aires, Argentina.

Respuestas al "Informe" del administrador Miguel de Pereyra. (4 de septiembre de 1788. Sala IX, Legajo 17-8-6, sin número de documento, foja 7). Archivo General de la Nación, Apóstoles, Argentina.

Respuestas al "Informe" del administrador Pedro Fontela. (13 de septiembre de 1788). (Sala Ix, Legajo 17-8-6, sin número de documento, foja 8). Archivo General de la Nación, Concepción, Argentina.

Respuestas al "Informe" del administrador Pedro Nolasco Alfaro. (3 de septiembre de 1788). (Sala Ix, Legajo 17-8-6, sin número de documento, foja 6v.). Archivo General de la Nación, San Carlos, Argentina.

Sarreal, J. (2014). The Guarani and Their Missions: A Socioeconomic History. California, Estados Unidos de América: Stanford University Press.

Silva, J. y Escobar, A. (Coords.). (2000). Mercados indígenas en México, Chile y Argentina. Siglos xVII-XIx. México: Instituto Mora, cIEsas.

Susnik, B. (1965). El indio colonial del Paraguay. El guaraní colonial 1. Asunción, Paraguay: Museo Etnográfico Andrés Barbero.

Visita a San Apóstoles de Francisco Bruno de Zabala, capitán de Regimiento de Dragones de Buenos Aires y gobernador de los Treinta Pueblos. (3 de septiembre de 1787). Sala Ix, Legajo 39-5-1, documento 259 expediente 20, foja 3). Archivo General de la Nación, Buenos Aires, Argentina.

Visita a San Nicolás de Francisco Bruno de Zabala, capitán de Regimiento de Dragones de Buenos Aires y gobernador de los Treinta Pueblos. (3 de septiembre de 1787). Sala Ix, Legajo 39-5-1, documento 259 expediente 20, foja 3). Archivo General de la Nación, Buenos Aires, Argentina.

Wallerstein, I. (2004). El moderno sistema mundial. La segunda era de gran expansión de la economía-mundo capitalista, 1730-1850. Buenos Aires, Argentina: Siglo xxi Editores.

Wilde, G. (2009). Religión y poder en las misiones de guaraníes. Buenos Aires, Argentina: sB Ediciones. 
Lía Quarleri

Argentina. Doctora en Antropología social por la Universidad de Buenos Aires. Investigadora adjunta en el Consejo Nacional de Investigaciones Científicas y Técnicas (Conicet) y profesora adjunta en el Instituto de Altos Estudios Sociales de la Universidad Nacional de San Martín. Líneas de investigación: estudio de las políticas coloniales en la frontera hispano-portuguesa con especial hincapié en las relaciones hispano-indígenas. Publicaciones recientes: New forms of colonialism on the frontiers of Hispanic America: Assimilationist projects and economic disputes (Río de la Plata, late eighteenth century). (2017), D. Tricoire (Ed.). Londres, Nueva York: Palgrave MacMillan. 